\title{
Penganuh Breed terhadap Fertilitas, Daya Tetas dan Kematian Embrio pada Telur Itik Alabio, Mojosari dan Persilangan Peking $x$ Mojosari Putih
}

\section{(Effect of Breed on Fertility, Hatchability and Embryo Mortality of Alabio, Mojosari and Peking x White Mojosari Crossbred Duck Eggs)}

\author{
Kumalawati DS, Susanti T \\ Balai Penelitan Ternak, PO Box 221 Bogor 16002 \\ sarkoem@gmail.com
}

\begin{abstract}
The study was conducted to investigate the effect of breed on fertility, hatchability and embryo mortality of Alabio, Mojosari and Peking x White Mojosari crossbred duck eggs. A total 22,160 eggs were selected and incubated for 28 days with the same procedure. All the data was examined for fertility, hatchability and embryo mortality during incubation and analyzed by ANOVA for a complete randomized design, using Duncan procedure of SAS. The result of the study revealed that fertility of three breeds showed a significant difference $(\mathrm{P} \leq 0.05)$ but did not on hatchability and total embryo mortality during incubation $(\mathrm{P}>0.05)$. Fertility of the three breeds was quite high with values above $90 \%$, on the contrary, the hatchability of eggs was recorded low, with the value between $50-55 \%$ due to high embryo mortality during incubation with the value between $40-43 \%$. The highest embryo mortality among the incubation periods was found at 26-28 day of incubation, and then followed by embryonic mortality at 16-25 d, 0-5 d, and 6-15 d, respectively. From the present study, it can be concluded that breed had significant effect on fertility but didn't on hatchability and embryo mortality of Alabio, Mojosari and Peking x White Mojosari crossbred duck eggs.
\end{abstract}

Key words: Breed, fertility, hatchability, embryo mortality, duck

\section{ABSTRAK}

Penelitian ini bertujuan untuk mengetahui pengaruh breed terhadap fertilitas, daya tetas dan kematian embrio telur itik Alabio, Mojosari dan persilangan Peking x Mojosari Putih. Total 22.160 butir telur dari ketiga breed diseleksi dan diinkubasi selama 28 hari dengan prosedur yang sama. Seluruh data dihitung fertilitas, daya tetas, dan kematian embrio selama masa inkubasi inkubasi dan dianalisa menggunakan ANOVA untuk Rancangan Acak Lengkap dengan metode Duncan (SAS). Hasil dari penelitian menunjukkan bahwa fertilitas pada ketiga breed menunjukkan perbedaan yang nyata $(\mathrm{P} \leq 0,05)$, tetapi tidak pada daya tetas dan total kematian embrio selama inkubasi $(\mathrm{P}>0,05)$. Fertilitas ketiga breed cukup tinggi, dengan nilai diatas $90 \%$, namun sebaliknya, daya tetas tercatat rendah, yaitu berkisar antara 50-55\% dikarenakan kematian embrio yang tinggi selama inkubasi yaitu berkisar 40-43\%. Kematian embrio tertinggi selama inkubasi ditemukan pada hari ke 26-28, diikuti hari ke 1625, 0-5 dan 6-15 masa inkubasi. Dari hasil penelitian dapat disimpulkan bahwa breed mempengaruhi fertilitas, namun tidak terhadap daya tetas dan total kematian embrio itik Alabio, Mojosari dan persilangan Peking x Mojosari Putih selama inkubasi.

Kata kunci: Breed, fertilitas, daya tetas, kematian embrio, itik 


\section{PENDAHULUAN}

Usaha ternak itik cukup berkembang di Indonesia saat ini, apalagi daging dan telur itik menjadi pangan alternatif yang lebih terjangkau dibanding daging sapi dan ayam kampung yang relatif lebih mahal (Sattyananda 2018). Selain itu itik telah terbukti memiliki daya tahan lebih kuat terhadap penyakit serta lebih mampu beradaptasi terhadap kondisi lingkungan dibanding ayam (Adzitey \& Adzitey 2011). Berdasarkan data Statistik Peternakan dan Kesehatan Hewan yang dikeluarkan oleh Ditjen PKH (2018), produksi daging itik pada tahun 2018 sebesar 38.044 ton atau naik 4,54\% dari tahun 2017, dan merupakan penyumbang 1,06 \% dari total produksi daging nasional, sedangkan sebagai penghasil telur, telur itik menyumbang $13.42 \%$ dari total produksi telur nasional, meskipun produksi telur turun 1,24 \% dari tahun sebelumnya menjadi 298.943 ton pada tahun 2018.

Dari beberapa jenis itik di Indonesia, itik Mojosari banyak dikembangkan sebagai itik petelur karena memiliki produksi telur yang tinggi, begitu pula Alabio yang dikenal sebagai itik dual fungsi yaitu petelur dan pedaging (Darmawati et al. 2016). Sedangkan untuk pedaging, itik persilangan Peking x Mojosari Putih (PMp) disukai karena terbukti mampu mencapai berat potong yaitu 1.237 gram pada umur 6 minggu (Purba et al. 2017).

Menurut King’ori (2011) industri unggas pada semua skala operasional bergantung sepenuhnya pada ketersediaan bibit anak, dimana fertilitas dan daya tetas adalah dua parameter utama yang mempengaruhi ketersediaan bibit tersebut. Fertilitas sendiri dipengaruhi oleh beberapa faktor, yaitu faktor yang berasal dari induk pejantan, induk betina atau manajemen di kandang. Faktor yang berasal dari induk jantan dan betina, antara lain umur induk, nutrisi pakan induk, perilaku kawin dan durasi kesuburan induk betina. Sementara itu rasio jantan dan betina saat perkawinan alami serta teknik inseminasi buatan menjadi faktor yang mempengaruhi fertilitas dari sisi manajemen di kandang (Brillard 2003). Berdasarkan hasil penelitian sebelumnya diketahui fertilitas itikitik di Indonesia cukup beragam yaitu berkisar antara 85-95\% (Meliyati et al. 2012; Darmawati et al. 2016).

Berbeda halnya dengan fertilitas, daya tetas sebagian besar dipengaruhi oleh faktor lingkungan atau kondisi selama inkubasi. Dalam hal ini, kondisi yang dimaksud adalah suhu, kelembaban relatif, ventilasi dan pembalikan telur (Boleli et al. 2016; Lopez et al. 2018), dimana kebutuhannya berbeda pada setiap tahap perkembangan embrio selama inkubasi (Sözcü \& İpek 2013). Meskipun faktor lingkungan memiliki pengaruh lebih besar, faktor dari ternak sendiri memiliki andil yang penting terhadap keberhasilan suatu inkubasi. Beberapa faktor yang mempengaruhi daya tetas yang berasal dari ternak antara lain: kesehatan induk, nutrisi dan umur induk, serta ukuran, berat dan kualitas telur (Abudabos 2010; King'ori 2011; El-Hanoun et al. 2012; Iqbal et al. 2014; Abudabos et al. 2017). Dalam beberapa penelitian, daya tetas itik dengan inkubasi secara buatan tercatat rendah. Daya tetas itik di Indonesia berkisar antara 50-75\% (Meliyati et al. 2012; Darmawati et al. 2016)

Selain beberapa faktor di atas, beberapa penelitian telah dilakukan untuk mengetahui pengaruh breed terhadap fertilitas dan daya tetas. Abudabos (2010); Awad (2013); Verma et al. (2018) menyebutkan bahwa breed memiliki pengaruh nyata terhadap fertilitas dan daya tetas, namun beberapa penelitian lain menyebutkan sebaliknya (Miazi et al. 2012; Rashid et al. 2013).

Untuk itu perlu dilakukan pengamatan fertilitas dan daya tetas pada tiga breed itik yang berbeda yaitu tipe pedaging yang diwakili itik PMp, tipe petelur yang diwakili itik 
Mojosari dan tipe dual fungsi yang diwakili itik Alabio, dengan tujuan untuk mengetahui pengaruh breed terhadap fertilitas dan daya tetas itik di Indonesia.

\section{MATERI DAN METODE}

Penelitian dilakukan selama 7 bulan dari bulan Desember 2017 sampai bulan Januari 2018, di hatchery stasiun percobaan itik Balitnak, Ciawi, menggunakan 22.160 butir telur tetas yang terdiri dari 8.688 butir telur Alabio, 5.909 butir telur Mojosari dan 7.563 butir telur persilangan Peking x Mojosari Putih (PMp). Telur didapatkan dari induk betina dengan umur 35-78 minggu yang dipelihara secara kelompok dan dikawinkan secara alami dengan perbandingan jantan:betina 1:4. Mesin tetas yang digunakan terdiri dari setter dan hatcher. Setter yang digunakan merupakan produksi dari Multiplo dengan kapasitas 1.500 butir telur itik untuk setter 1, dan 3.000 butir untuk setter 2. Hatcher yang digunakan terdiri dari mesin 1 produksi Multiplo dengan kapasitas 1.200 butir dan mesin 2 produksi Aladin dengan kapasitas 1.700 butir.

\section{Pengumpulan dan seleksi telur}

Pengumpulan telur dilakukan selama satu minggu untuk setiap pengulangan, sehingga diperoleh telur tetas dengan lama penyimpanan 1-7 hari. Hal ini sesuai dengan rekomendasi Onbaşılar et al. (2007) bahwa lama penyimpanan telur itik tidak boleh lebih dari 7 hari. Telur yang telah dikumpulkan, kemudian diseleksi untuk mendapatkan telur tetas. Kriteria telur yang diseleksi antara lain telur retak, telur abnormal (terlalu lonjong atau terlalu bulat) dan telur kotor. Telur tetas disimpan dalam suhu ruangan $\left(25-30^{\circ} \mathrm{C}\right)$ sebelum ditetaskan.

\section{Persiapan mesin tetas}

Sebelum digunakan, mesin tetas dibersihkan sebaik mungkin dari residu inkubasi sebelumnya, kemudian difumigasi menggunakan campuran kalium permanganate dan formalin selama 10-15 menit dalam keadaan tertutup. Selanjutnya mesin tetas dihidupkan dan kondisi di dalam mesin diatur pada suhu $37,5-38^{\circ} \mathrm{C}$ dan kelembaban $60-65 \%$ selama 24 jam sebelum digunakan.

\section{Inkubasi telur}

Seperti halnya mesin tetas, telur tetas yang telah disusun pada rak telur difumigasi dengan campuran kalium permanganate dan formalin selama 10-15 menit dalam ruangan fumigasi tertutup untuk membunuh bakteri di permukaan kerabang telur (Furuta \& Maruyama 1981), sebelum dimasukkan ke dalam mesin tetas. Pada hari ke 1-25, telur ditetaskan didalam setter. Kondisi di dalam setter dijaga pada suhu $37,5-38^{\circ} \mathrm{C}$ dan kelembaban 60-65\% dengan sistem ventilasi dan pembalikan telur setiap satu jam sekali. Selanjutnya telur dipindahkan dan ditetaskan dalam hatcher pada suhu $36,5-37^{\circ} \mathrm{C}$ dan kelembaban 65-75\% selama 3 hari terakhir tanpa dilakukan pembalikan. Candling dilakukan sebanyak 3 kali selama proses inkubasi, yaitu pada hari ke 5, hari ke 15 dan hari ke 25 pada saat pemindahan. Candling dilakukan untuk mengetahui perkembangan embrio selama inkubasi. 


\section{Koleksi data}

Data yang dikoleksi antara lain jumlah telur tetas (masuk setter), jumlah telur fertil yang didapatkan dari hasil candling pertama, telur yang mati di setiap candling dan total telur yang tidak menetas pada akhir inkubasi. Kemudian dihitung fertilitas, daya tetas dari total telur, dan daya tetas dari telur fertil dan persentase kematian embrio selama inkubasi. Persentase kematian embrio selama inkubasi dipetakan menjadi 4 periode kematian, yaitu kematian hari ke-1-5 (early dead) yang didapat dari candling 1, kematian hari ke 6-15 (mid dead) dan hari ke 16-25 (late dead) yang didapat dari candling kedua dan ketiga, serta kematian hari ke 26-28 inkubasi (pipped dead) yang diketahui dari jumlah telur yang tidak menetas. Rumus perhitungan variabel penelitian dapat dilihat dibawah ini:

Fertilitas $\quad=\frac{\text { Jumlah telur fertil }}{\text { Jumlah telur tetas }} \times 100 \%$

Daya tetas telur total $=\frac{\text { Jumlah telur menetas }}{\text { Jumlah telur yang ditetaskan }} \times 100 \%$

Daya tetas telur fertil $=\frac{\text { Jumlah telur menetas }}{\text { Jumlah telur fertil }} \times 100 \%$

Persentase kematian embrio $\quad=\frac{\text { Jumlah embrio mati selama inkubasi }}{\text { Jumlah telur fertil }} \times 100 \%$

Persentase kematian embrio ke 1-5 = Jumlah embrio mati pada candling pertama $\times 100 \%$

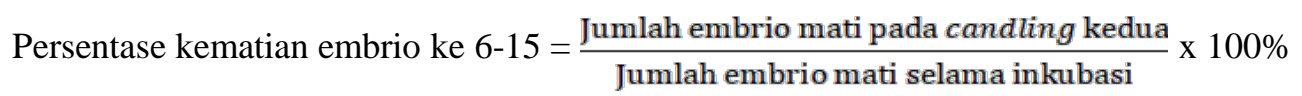

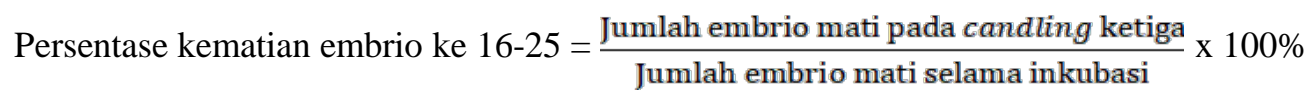

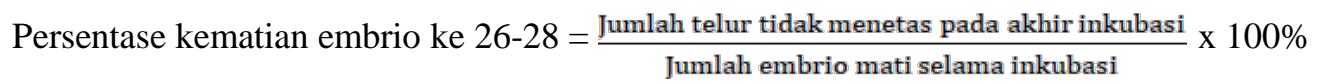

\section{Analisis statistik}

Semua variabel ketiga breed dianalisis menggunakan prosedur ANOVA Rancangan Acak Lengkap dengan satu factorial (SAS system). Pengaruh breed terhadap variabel dianalisis menggunakan metode Duncan dan hasilnya ditampilkan sebagai mean \pm SEM (standard error of the mean) (Mattjik \& Sumertajaya 2000). Hasil dikatakan berbeda nyata jika $\mathrm{P} \leq 0,05$, dan berbeda sangat nyata jika $\mathrm{P} \leq 0,001$. 


\section{HASIL DAN PEMBAHASAN}

Pengaruh breed terhadap fertilitas, daya tetas dan kematian embrio selama inkubasi ditampilkan pada Tabel 1.

Tabel 1. Fertilitas, daya tetas dan kematian embrio pada setiap breed

\begin{tabular}{lcccc}
\hline \multirow{2}{*}{ Breed } & Fertilitas & \multicolumn{2}{c}{ Daya tetas (\%) } & \multirow{2}{*}{ Kematian embrio } \\
\cline { 3 - 4 } & $(\%)$ & dari total telur & dari telur fertil & $(\%)$ \\
\hline Alabio & $93,97 \pm 3,27^{\text {ab }}$ & $50,85 \pm 7,57$ & $54,24 \pm 8,65$ & $43,12 \pm 8,84$ \\
Mojosari & $95.10 \pm 2,28^{\text {a }}$ & $55,21 \pm 7,59$ & $58,17 \pm 8,64$ & $39,89 \pm 8,88$ \\
PMp & $92,41 \pm 4,28^{\mathrm{b}}$ & $51,48 \pm 7,18$ & $55,76 \pm 7,89$ & $40,93 \pm 7,63$ \\
P & $* *$ & ns & ns & ns \\
\hline
\end{tabular}

a-b pada kolom yang sama, , nilai dengan huruf yang berbeda menunjukkan perbedaan yang nyata (n.s.; non significant, **: $\mathrm{P} \leq 0,05$ )

\section{Fertilitas}

Pada Tabel 1 terlihat bahwa fertilitas ketiga breed itik cukup tinggi yaitu diatas 90\%, dengan nilai tertinggi ke rendah berturut-turut adalah Mojosari, Alabio dan PMp. King'ori (2011) menyebutkan bahwa unggas tipe ringan memiliki fertilitas yang lebih tinggi. Hasil ini dapat diasosiasikan dengan perilaku perkawinan induk jantan dan betina tipe ringan, biasanya itik petelur lebih baik dibandingkan dengan tipe berat yang ditunjukkan oleh itik pedaging. Fertilitas ketiga breed tidak jauh berbeda dengan hasil penelitian sebelumnya (Darmawati et al. 2016; Meliyati et al. 2012).

Tabel 1, menunjukkan Mojosari secara nyata memiliki fertilitas lebih tinggi dibanding PMp dengan selisih lebih dari $2 \%(\mathrm{P} \leq 0,05)$. Hasil ini sesuai dengan penelitian Awad (2013) dan Verma et al. (2018) yang menyebutkan bahwa breed memiliki pengaruh yang nyata terhadap fertilitas. Akan tetapi, tidak ditemukan perbedaan yang nyata $(\mathrm{P}>0,05)$ diantara fertilitas Alabio dengan PMp dan Mojosari. Hal ini disebabkan adanya range umur induk betina yang cukup jauh yaitu antara 35-78 minggu pada ketiga breed. Umur induk betina memiliki pengaruh yang nyata terhadap fertilitas (Hocking \& Bernard 2000; Elibol et al. 2002; El-Hanoun et al. 2012). Fertilitas terbaik didapat saat umur induk 36-55 minggu, diikuti induk tua dan terakhir induk muda (El-Hanoun et al. 2012) dan pada populasi dengan sistem perkawinan alami, fertilitas optimal dapat dipertahankan dengan pengontrolan berat badan, minimal sampai umur 60 minggu (Hocking \& Bernard 2000).

\section{Daya tetas}

Daya tetas dari total telur ketiga breed itik rendah yaitu berkisar 50-55 \%. Sejalan dengan fertilitasnya, Mojosari memiliki daya tetas tertinggi diantara kedua breed yang lain. Pada hasil pengamatan, daya tetas Alabio dan PMp berbanding terbalik dengan fertilitasnya. Itik Alabio memiliki daya tetas terendah dibandingkan dengan Mojosari dan PMp. Daya tetas Alabio, Mojosari, dan PMp pada hasil penelitian juga tidak jauh berbeda dengan penelitian yang dilakukan Darmawati et al. (2016) dan Meliyati et al. (2012).

Rendahnya daya tetas dapat disebabkan oleh tidak tepatnya manajemen ternak di farm, ketidaktepatan pengaturan suhu dan kelembaban relatif, penanganan telur yang 
kurang baik, serta umur induk (Hocking \& Bernard 2000; Elibol et al. 2002; Ernst et al. 2004; Abudabos 2010; van den Brand et al. 2016). Telur yang dihasilkan dari induk muda maupun induk tua cenderung memiliki daya tetas yang lebih rendah dibanding induk dewasa. Pada telur induk muda, kematian embrio pada minggu pertama dan kedua sering ditemukan (Hocking \& Bernard 2000). Pada telur induk tua kualitas telur cenderung kurang baik karena kualitas telur menurun seiring bertambahnya umur ternak, baik kualitas dalam telur yang mendukung perkembangan embrio, maupun kualitas kerabang telur yang menyebabkan meningkatnya resiko retak kerabang. (Jabbar et al. 2019). Pada penelitian proses seleksi telur dilakukan dengan mata telanjang, sedangkan retak rambut pada kerabang telur itik umumnya sulit diidentifikasi tanpa metode candling. Hal ini menyebabkan lolosnya telur retak masuk ke dalam hatchery yang menjadi pintu masuknya mikrobia ke dalam telur dan menyebabkan kematian embrio pada setiap tahap inkubasi.

Pada penelitian, pengaturan suhu maupun kelembaban selama masa inkubasi pada semua telur adalah sama. Menurut El-Hanoun et al. (2012), prosedur selama inkubasi perlu disesuaikan dengan umur induk, dimana daya tetas terbaik didapatkan pada kelompok telur dari induk berumur 36-55 minggu dengan kelembaban inkubasi hari ke $14-24$ sebesar $65 \%$.

Daya tetas dari total telur tetas pada ketiga breed itik tidak menunjukkan perbedaan yang nyata $(\mathrm{P}>0,05)$. Hal ini sama dengan penelitian sebelumnya (Miazi et al. 2012; Rashid et al. 2013) yang menyebutkan bahwa breed tidak berpengaruh nyata pada daya tetas. Daya tetas dari telur fertil dapat dijadikan ukuran efisiensi suatu inkubasi. Pada penelitian, kondisi lingkungan selama inkubasi adalah sama untuk ketiga breed itik. Tabel 1, menunjukkan bahwa daya tetas telur fertil tertinggi didapatkan pada Mojosari. Hal ini berarti kondisi inkubasi pada penelitian, paling sesuai untuk telur Mojosari dibandingkan dengan kedua breed lainnya.

\section{Kematian embrio}

Kematian embrio hasil penelitian pada ketiga breed sangat tinggi berkisar antara 4043\% dengan kematian tertinggi ditemukan pada kelompok telur Alabio. Pada Tabel 1, menunjukkan breed tidak berpengaruh nyata $(\mathrm{P}>0,05)$ terhadap kematian embrio selama inkubasi.

Penyebab tingginya kematian embrio dapat disebabkan karena kontaminasi bakteri dan jamur, penyimpanan telur yang kurang baik (suhu ruang penyimpanan), penyakit, genetic, kualitas telur dan kerabang yang rusak, serta kondisi inkubasi yang tidak tepat (Onbaş1lar et al. 2007; Abudabos 2010; van der Pol et al. 2013; van den Brand et al. 2016; Addo et al. 2018; Jabbar et al. 2019).

Tabel 2. Kematian embrio selama inkubasi

\begin{tabular}{lllll}
\hline \hline Breed & Hari ke 0-5 & Hari ke 6-15 & Hari ke 16-25 & Hari ke 26-28 \\
\hline Alabio & $13,03 \pm 4,51$ & $4,05 \pm 4,56$ & $36,68 \pm 12,72^{\mathrm{a}}$ & $46,24 \pm 10,86^{\mathrm{a}}$ \\
Mojosari & $15,75 \pm 7,55$ & $4,32 \pm 5,10$ & $27,63 \pm 10,18^{\mathrm{b}}$ & $52,30 \pm 11,34^{\mathrm{a}}$ \\
PMp & $16,66 \pm 8,63$ & $6,75 \pm 6,99$ & $43,16 \pm 11,17^{\mathrm{a}}$ & $33,74 \pm 7,67^{\mathrm{b}}$ \\
P & ns & ns & $* * *$ & $* * *$ \\
\hline
\end{tabular}

a,b pada kolom yang sama, nilai dengan huruf yang berbeda menunjukkan perbedaan yang nyata (n.s.; non significant, ***: $\mathrm{P} \leq 0,001$ ) 
Pengaruh breed terhadap kematian embrio di setiap tahap tercantum pada Tabel 2. Hasil penelitian menunjukkan, terlihat perbedaan yang sangat nyata pada kematian hari ke 26-28 dan hari ke 16-25 masa inkubasi $(\mathrm{P} \leq 0,001)$. Sebagian besar kematian embrio selama inkubasi merupakan kontribusi dari kematian hari ke 26-28 (pipped dead), disusul kematian embrio hari ke 16-25 (late dead), kematian embrio hari ke 0-5 (early dead) dan terakhir kematian embrio hari ke 6-15 (mid dead).

\section{Kematian embrio hari ke 0-5 (Early dead)}

Pada Tabel 2, ditunjukkan bahwa kontribusi kematian embrio hari ke 0-5 terhadap kematian embrio selama inkubasi pada ketiga breed tidak jauh berbeda $(\mathrm{P}>0,05)$, yaitu berkisar antara 13-16\%. Kematian embrio pada awal inkubasi biasanya merupakan dampak dari penanganan telur yang kurang baik di kandang, sebelum masuk setter atau perlakuan diantaranya. Pada penelitian telur disimpan pada suhu ruangan $\left(25-30^{\circ} \mathrm{C}\right)$ selama 7 hari sebelum ditetaskan. Penyimpanan telur pada suhu ruangan yang mendekati suhu inkubasi dibandingkan pada suhu dingin $\left(18^{\circ} \mathrm{C}\right)$ dalam jangka waktu yang lama akan memacu perkembangan embrio terlalu awal (advance blastoderm development) dan menyebabkan meningkatnya kematian embrio pada awal inkubasi (Addo et al. 2018).

\section{Kematian embrio hari ke 6-15 (Mid dead)}

Pada penelitian, kontribusi kematian embrio hari ke 6-15 terhadap kematian embrio selama inkubasi pada ketiga breed tidak jauh berbeda $(\mathrm{P}>0,05)$ yaitu berkisar antara 47\%, dengan PMp terlihat sedikit lebih tinggi dari yang lain. Kematian embrio pada hari ke 6-15 biasanya dikaitkan pada kekurangan nutrisi pada pakan induk atau abormalitas pada embrio (Abudabos 2010). Pada induk yang dipelihara secara kelompok, persaingan dalam makan menyebabkan setiap induk tidak selalu mendapatkan asupan nutrisi yang sama sesuai dengan kebutuhannya dan pada akhirnya menyebabkan perbedaan kualitas telur yang ditetaskan.

\section{Kematian embrio hari ke 16-25 (Late dead)}

Dari hasil penelitian dapat dilihat bahwa kematian embrio pada hari ke 16-25 pada Alabio dan PMp memiliki kontribusi pada kematian embrio selama inkubasi 9-15\% jauh lebih tinggi dibanding Mojosari $(\mathrm{P} \leq 0,001)$. Pada penelitian, kondisi lingkungan selama inkubasi sangat mempengaruhi terjadinya kematian embrio minggu ketiga masa inkubasi. El-Hanoun et al. (2012) merekomendasikan kelembaban dalam mesin tetas pada hari ke 14-24 masa inkubasi harus diatur sesuai dengan umur induk untuk mendapatkan daya tetas yang baik. Pengaturan kelembaban yang kurang tepat dan terlalu rendah akan menambah persentase kematian sebesar 3\% pada periode ini (van der Pol et al. 2013). Kematian embrio pada periode ini juga dapat diakibatkan posisi abnormal embrio, komplikasi selama proses perubahan fisiologis embrio, dan gen yang mematikan (Abudabos 2010).

\section{Kematian embrio hari ke 26-28 (Pipped dead)}

Beberapa penelitian menyebutkan bahwa tiga hari terakhir masa inkubasi merupakan periode paling kritis dalam suatu proses inkubasi (Peñuela \& Hernandez 2018). Pada hasil penelitian kematian embrio paling banyak ditemukan pada masa ini meskipun persentase kematian PMp mencapai 33\% jauh lebih baik dibanding dua breed 
lainnya, dengan selisih $12-19 \%(\mathrm{P} \leq 0,001)$. Hasil ini sama dengan penelitian sebelumnya yang dilakukan Abudabos (2010). Tingginya kematian embrio pada penelitian disebabkan penanganan telur saat transfer dari setter ke hatcher kurang baik atau terlalu kasar. Proses penanganan telur yang terlalu kasar maupun pembalikan telur yang tidak benar dapat menyebabkan malposisi pada akhir perkembangan embrio (Rideout 2012). Penyebab kematian yang lain pada penelitian adalah kondisi lingkungan inkubasi (kelembaban) yang kurang tepat. Pada penelitian kelembaban pada 3 hari terakhir masa inkubasi adalah 65-75\%, sedangkan menurut El-Hanoun et al (2012) adalah 80\% dengan daya tetas mencapai $72 \%$ pada kelompok umur 36-55 minggu.

Lebih lanjut Ernst et al. (2004) menjelaskan beberapa masalah yang timbul menjelang akhir inkubasi adalah sebagai berikut: (1) Suhu yang rendah disertai kelembaban relatif yang tinggi akan menyebabkan embrio mati sebelum memecah kerabang telur, jika hidup terlihat lemah dan lesu; (2) Suhu yang terlalu tinggi disertai kelembaban relatif yang rendah akan menyebabkan anak mati setelah memecah kerabang telur, jika hidup terlihat kurus; (3) Kelembaban relatif terlalu rendah maka anak akan terjebak dan menempel pada kerabang saat memecah kerabang telur.

Pipped dead menunjukkan kegagalan anak dalam memecah kerabang saat menetas. Semakin tebal kerabang, maka kemungkinan anak berhasil memecah kerabang semakin rendah (Abudabos 2010). Abdurehman \& Urge (2016) pada penelitiannya menambahkan terdapat pengaruh yang nyata antara breed terhadap berat kerabang telur. Secara tidak langsung hasil penelitian mengindikasikan bahwa kualitas kerabang ketiga breed berbeda dengan ketebalan paling tipis didapat pada telur PMp, dan diperlukan penelitian lebih lanjut untuk membuktikannya.

\section{KESIMPULAN}

Dari hasil penelitian dapat disimpulkan bahwa, breed berpengaruh terhadap fertilitas telur itik Alabio, Mojosari dan PMp, namun tidak mempengaruhi daya tetas dan total kematian embrio selama inkubasi. Secara umum kelompok telur Mojosari menunjukkan performa terbaik dibandingkan dengan dua breed lainnya. Hasil penelitian mengarahkan bahwa manajemen memiliki peran sangat penting terhadap hasil suatu penetasan sehingga perlu adanya penyesuaian manajemen baik di kandang maupun di hatchery terhadap setiap breed yang berbeda untuk mendapatkan hasil bibit yang optimal.

\section{UCAPAN TERIMA KASIH}

Penulis mengucapkan terima kasih kepada teknisi dan karyawan stasiun percobaan komplek itik atas bantuan dan dukungannya selama penelitian berlangsung.

\section{DAFTAR PUSTAKA}

Abudabos A. 2010. The effect of broiler breeder strain and parent flock age on hatchability and fertil hatchability. Int J Poult Sci. 9:231-235.

Abudabos AMI, Aljumaah RSI, Algawaan ASI, Al-Sornokh HI, Al-Atiyat RMI. 2017. Effects of hen age and egg weight class on the hatchability of free range indigenous chicken eggs. Braz J Poult Sci. 19:033-040.

Abdurehman A, Urge M. 2016. Evaluation of fertility, hatchability and egg quality of Rural Chicken in Gorogutu District, Eastern Hararghe, Ethiopia. Asian J Poult Sci. 10:111116. 
Addo A, Hamidu JA, Ansah AY, Adomako K. 2018. Impact of egg storage duration and temperature on egg quality, fertility, hatchability and chick quality in Naked Neck Chickens. Int J Poult Sci. 17:175-183.

Adzitey F, Adzitey SP. 2011. Duck production: Has a potential to reduce poverty among rural household in Asian communities - A Review. J World's Poult Res. 1:7-10.

Awad AL. 2013. Field study on hatching traits of duck eggs under Egyptian environmental conditions. Egypt Poult Sci. 33:849-863.

Boleli IC, Morita VS, Matos Jr JB, Thimotheo M, Almeida VR. 2016. Poultry egg incubation: integrating and optimizing production efficiency. Braz J Poult Sci. Special Issue 2 Incubation:001-016.

Brillard JP. 2003. Practical aspect of fertility in poultry. World's Poult Sci J. 81.

Darmawati D, Rukmiasih, Afnan R. 2016. Daya tetas telur itik Cihateup dan Alabio. J Ilmu Produksi Teknologi Hasil Peternakan. 4:257-263.

Ditjen PKH. 2018. Statistik peternakan dan kesehatan hewan 2018. Jakarta (Indonesia): Direktorat Jenderal Peternakan dan Kesehatan Hewan, Kementerian Pertanian.

El-Hanoun AM, Rizk RE, Shahein EHA, Hassan NS, Brake J. 2012. Effect of incubation humidity and flock age on hatchability traits and posthatch grow in Pekin ducks. Poult Sci. 91:2390-2397.

Elibol O, Peak SD, Brake J. 2002. Effect of flock age, length of egg storage, and frequency of turning during storage on hatchability of broiler hatching eggs. Poult Sci. 81:945-950.

Ernst RA, Bradley FA, Delany ME, Abbot UK, Craig RM. 2004. Common incubation problem: Causes and remedies. Oakland (USA): Division of Agriculture and Natural Resources Publication, University of California [Internet]. [cited 6 July 2018]. Available from: https://anrcatalog.ucanr.edu/pdf/8127.pdf.

Furuta K, Maruyama S. 1981. Bacterial contamination on eggs during incubation and hatching, and of fluffs of newly-hatched chicks. Br Poult Sci. 22:247-254.

Hocking PM, Bernard R. 2000. Effects of the age of male and female broiler breeders on sexual behavior, fertility and hatchability of eggs. Br Poult Sci. 41:370-377.

Iqbal J, Khan SH, Mukhtar N, Ahmed T, Pasha RA. 2014. Effects of egg size (weight) and age on hatching performance and chick quality of broiler breeder. J Appl Anim Res. 44:54-64.

Jabbar A, Hameed A, Yousaf A, Riaz A, Ditta YA. 2019. The influence of hairline crack eggs on hatchery parameters and performance of chicks. World's Vet J. 9:76-83.

King'ori AM. 2011. Review of the faktors that influence egg fertility and hatchability in poultry. Int J Poult Sci. 10:483-492.

Lopez JC, Kitto L, Hulet RM. 2018. Effect of eggshell temperature on survival rate, development at hatch, and 7-day growth [Internet]. [cited 30 January 2018]. Available from: https://academic.oup.com/japr/advance-article-abstract/doi/10.3382/japr/pfx065/ 4791175.

Mattjik AA, Sumertajaya M. 2000. Perancangan percobaan dengan aplikasi SAS dan MINITAB. Jilid 1. Bogor (Indonesia): IPB Press.

Meliyati N, Nova K, Septinova. 2012. Pengaruh umur telur tetas itik Mojosari dengan inkubasi kombinasi terhadap fertilitas dan daya tetas. J Ilmiah Peternakan Terpadu. 1.

Miazi OM, Miah G, Miazi MM, Uddin MM, Hassan MM, Faridahsan M. 2012. Fertility and hatchability of Fayoumi and Sonali chicks. Scholarly J Agric Sci. 2:83-86. 
Onbaşılar EE, Poyraz Ö, Erdem E. 2007. Effects of egg storage period on hatching egg quality, hatchability, chick quality and relatif growth in Pekin ducks. Arch Geflügelk. 71:187-191.

Peñuela SA, Hernandez VA. 2018. Characterization of embryonic mortality in broilers. Rev MVZ Córdoba. 23:6500-6513.

Purba M, Sinurat AP, Susanti T. 2017. Performa tiga genotype itik pedaging (Peking, PMp, dan E-PMp) dengan pemberian dua jenis ransum selama enam minggu. Dalam: Puastuti W, Muharsini S, Inounu I, Tiesnamurti B, Kusumaningtyas E, Wina E, Herawati T, Hartati, Hutasoit R, et al., penyunting. Prosiding Seminar Nasional Teknologi Peternakan dan Veteriner. Bogor (Indonesia): Pusat Penelitian dan Pengembangan Peternakan. hlm. 388-396.

Rashid A, Khan SH, Abbas G, Amer MY, Khan MJA, Iftikhar N. 2013. Effect of egg weight on hatchability and hatchling weight in Fayoumi, Desi and Crossbred (Rhode Island Red X Fayoumi) chickens. Vet World. 6:592-595.

Rideout BA. 2012. Investigating embryo deaths and hatching failure. Vet Clin Exot Anim. 15:155-162.

Sattyananda D. 2018. Meneropong industri peternakan itik nasional [Internet]. [cited 27 August 2018]. Available from: https://www.poultryindonesia.com/meneropong-industripeternakan-itik-nasional.

Sözcü A, İpek A. 2013. Incubation conditions affect chick quality and broiler performance. J Agric Fac Uludag Univ. 27:139-146.

van den Brand H, Sosef MP, Lourens A, van Harn J. 2016. Effects of floor eggs on hatchability and later life performance in broiler chickens. Poult Sci. 95:1025-1032.

van der Pol CW, van Roovert-Reijrink IAM, Maatjens CM, van den Brand H, Molenaar R. 2013. Effect of relative humidity during incubation at a set eggshell temperature and brooding temperature posthatch on embryonic mortality and chick quality. Poult Sci. 92:2145-2155.

Verma AK, Pramanik PS, Singh KD, Panday G, Verma HC, Verma RK. 2018. Comparative assessment of fertility and hatchability of Kadaknath and Aseel fowls. Int J Curr Microbiol App Sci. 7:1238-1243. 